\title{
Metastatic Thyroid Gland Carcinoma
}

National Cancer Institute

\section{Source}

National Cancer Institute. Metastatic Thyroid Gland Carcinoma. NCI Thesaurus. Code C133193.

A carcinoma of the thyroid gland that has spread to another anatomic site. 